\title{
HISTORIAS DE VIDA DE PUNTARENAS: CASO DEL HOGAR DE ANCIANOS DE ESPARZA Y MIRAMAR, 2015-2016
}

\section{LIFE STORIES OF PUNTARENAS: THE NURSING HOMES OF ESPARZA AND MIRAMAR, 2015-2016}

\section{Kathia Cousin Brenes*}

\begin{abstract}
RESUMEN
En este artículo se analizan las historias de vida de los residentes de los asilos de ancianos de Esparza y Miramar, en el periodo 2015-2016, mediante la técnica de análisis de contenido, con el objetivo de investigar las distintas formas en las que se reconstruye la memoria $y$, al mismo tiempo, evidenciar cuáles son los efectos socioculturales de esa construcción. A partir de este estudio, se puede concluir que entre las personas participantes existe una tendencia a evocar el pasado como un "tiempo mejor", en relación con eventos significativos de sus vidas.
\end{abstract}

PALABRAS CLAVE: COSTA RICA * CIENCIAS SOCIALES* HISTORIA ORAL * MEMORIA * ANCIANO

\section{ABSTRACT}

This article intends, through the technique of content analysis, to analyze the life stories of the residents of the retirement homes of Esparza and Miramar, in the period 2015-2016, to investigate the different ways in which memory is reconstructed and, at the same time, highlighting the socio-cultural effects of this construction. From this study, it can be concluded that among the participants there is a tendency to evoke the past as a better time, in relation to significant events in their lives.

KEYWORDS: COSTA RICA * SOCIAL SCIENCES * ORAL HISTORY * MEMORY * ENDERLY

Sede del Pacífico de la Universidad de Costa Rica, Costa Rica.

kcousin4@gmail.com 


\section{INTRODUCCIÓN}

Después de la Segunda Guerra Mundial, surge y se consolida la "historia oral" 1 como una herramienta útil para el estudio en las ciencias sociales, cuyo propósito es estudiar diversas áreas poco analizadas en temas culturales, sociales y lingüísticos, entre otros.

Esta metodología cobra importancia en las ciencias sociales porque utiliza los testimonios o fuentes orales para reconstruir el pasado, permitiendo recuperar algo que no se encuentra o se ha dejado de lado, muchas veces, en la historia oficial. Así, la historia oral enlaza los tiempos y permite que la persona entrevistadora se acerque a los testimonios sobre el pasado, desde el presente. En ese marco, resulta interesante para el estudio de procesos históricos modernos, que la fuente oral va adquiriendo mayor peso entre las colectividades para "completar o contraponer las explicaciones contenidas en los documentos escritos" (Bermúdez y Rodríguez, 2009, p.321).

Este proyecto nace a raíz de los estudios de la autora en el Doctorado de Estudios de la Sociedad y la Cultura de la Universidad de Costa Rica, en el cual se revisan autores como Halbwachs (1975), Jelin (2002), Ricoeur (2010), Portelli (2014) y Kuri (2018), en temas relacionados con la memoria, la historia y la identidad, por mencionar algunos. También Arfuch (2002), quien plantea la importancia de recuperar la voz del "otro", mediante las "historias de vida".

Asimismo, esta investigación sigue la línea trazada por la Universidad de Costa RicaSede del Pacífico, ubicada en Puntarenas, Costa Rica, por medio de sus trabajos comunales TCU 461 "Gestión Ambiental a nivel comunal" (García, 2007) y el TCu 578 "Promoción de los Estilos de Vida Saludables de la Sede del Pacífico", los

1 La historia oral nació aproximadamente en 1948, época en la cual la sociedad pensaba que lo que no estaba escrito carecía de valor como documento histórico. Fue en la Universidad de Columbia, con Allan Nevis, quien reunió un material para la biografía del presidente Groover Cleveland, el cual resultó ser un proyecto exitoso (García y Sepúlveda, 1985) y logró establecer la técnica de investigación de la "historia de vida". cuales han propiciado acercamientos con adultos mayores ${ }^{2}$ en asilos de ancianos y centros diurnos de localidades como Miramar, Esparza, Puntarenas y Barranca, mediante talleres socioeducativos. De ahí que, al interactuar con este tipo de población, se fue gestando la idea de construir un archivo de memorias que -a futuro- podría ser utilizado para posteriores investigaciones sociales.

Para la reconstrucción de la memoria se recurrió al método de "historias de vida", la cual es una técnica cualitativa ubicada en el marco biográfico que, según Rodríguez, Gil y García (1996), permite analizar y revisar los relatos de una persona sobre su vida o momentos importantes. Aunado a esto, Bertaux (citado por Beltramino, 2007, p. 17), expone que con la historia de vida se puede utilizar la técnica de "modalidad hermenéutica", la cual consiste en el "descubrimiento de los significados, que transmiten las personas que relatan sus vidas y la modalidad etnosociológica, que reside en acceder a través de los relatos [...] relaciones $y$ normas $y$ procesos que estructuran su vida social" en una pluralidad de situaciones. En otras palabras, el análisis de los datos obtenidos implica una revisión de índole cualitativa.

También se usó la técnica de "análisis de contenido" para el estudio de las historias de vida. Esta es una herramienta que, según Pardinas (1991), permite la "clasificación de las diferentes partes de un escrito, conforme a categorías determinadas por el investigador, para extraer de ellos la información predominante" (p. 102).

Finalmente, las reflexiones que se proponen en este artículo surgen a partir de historias

2 Las personas adultas mayores son aquellas que sobrepasan los 65 años. Además, según la ley nro. 6739 Ley integral de la persona adulta mayor y su reglamento de Costa Rica (1982), a estos individuos se les debe brindar atención integral, ayudas técnicas si poseen alguna discapacidad, trato preferencial en instituciones, contar con servicios de atención, general o especializada. De igual forma, deben ser protegidas contra cualquier tipo de violencia, tienen derecho a una calidad de vida, amplia participación en actividades recreativas, entre otras cosas. 
de vida ${ }^{3}$, cuya memoria no es un "depósito pasivo de hechos, sino un activo proceso de creación de significados" (Portelli, 1991, p.45), sino que se encuentran anclados en legitimidades, tiempos y espacios de la vida social, así como, a las versiones que estos sujetos tienen de los acontecimientos. Por ende, en esta etapa se produce un silenciamiento de sus voces; estos protagonistas ya no tienen la oportunidad de dar sus testimonios, por lo que sus discursos, su palabra y los recuerdos que los codifican desaparecen.

\section{MATERIALES Y MÉTODOS}

En Costa Rica existen pocos estudios de historia oral ${ }^{4}$. En la provincia de Puntarenas, estos trabajos son aún más limitados, aunque en la Sede del Pacífico ${ }^{5}$ de la Universidad de

$3 \quad$ Este grupo de individuos representa a una población que no es económicamente activa dentro de la sociedad.

$4 \quad$ En cuanto a la reseña de historia oral en Costa Rica, Juan Rafael Quezada menciona que los primeros estudios están contenidos en la geografía lingüística de 1964. También comenta que, para 1971, la Universidad Nacional lanzó un concurso de biografías campesinas, el cual no contó con el apoyo necesario, situación que desmotivó a los promotores de esta técnica. Para 1980, destacan otros estudios de Quezada Camacho, siempre en el área de la geografía lingüística. Posteriormente, Eugenia Bozzoli, en 1982, realizó estudios sobre la oralidad de las comunidades indígenas (Quezada, 1990). A su vez, los estudios de historia oral que se realizan en Costa Rica están orientados, en su mayoría, a la preocupación por lo social, es decir, hacia el "cuestionamiento del status quo en el sentido más amplio, y el cuestionamiento de las formas clásicas de producción de conocimientos" (Quezada, 1990, p.179). Siguiendo esta trayectoria, en el ámbito universitario, Mario Samper utilizó fuentes orales para su proyecto de investigación de 1987, titulado "Autoconsumo para el mercado en fincas familiares 1850-1940". De igual manera, Víctor Hugo Acuña trabajó arduamente en "Aportes para la memoria popular", en 1982 (Quezada, 1990), por mencionar algunos trabajos sobresalientes.

$5 \quad$ Entre los proyectos más recientes de investigación con fuentes orales se encuentran: Recuperación de la memoria fotográfica y relatos de vida de los inmigrantes chinos en la ciudad de Puntarenas
Costa Rica ${ }^{6}$, se están realizando proyectos de investigación y acción social en la región, con el fin de rescatar este tipo de información de fuente primaria.

Para esta investigación se entrevistó a profundidad a 24 participantes (13 de Esparza y 11 de Miramar), con el fin de recuperar los testimonios de personas adultas mayores residentes de los Hogares de Ancianos de Miramar y Esparza que recordaban sus historias y mostraban interés en narrarlas voluntariamente. Para efectos del análisis, ambos grupos conforman un total en las tabulaciones de los datos. El análisis de los temas es de tipo cualitativo, mediante las siguientes categorías de investigación: edad de las personas adultas mayores, género, escolaridad, relatos del paisaje en su infancia $y$ trayectoria laboral.

Esta información se recopiló durante los años 2015 y 2016. Durante sus inicios se contó con la colaboración voluntaria de estudiantes de Trabajo Comunal Universitario

de Susan Chen Mok (550-B6-168) y Belleza de las curvas costeras y corporales: estereotipos de belleza y representaciones del cuerpo femenino 1950-2010 de Gloriana Rodríguez Corrales y Javier Madrigal Córdoba (550-B6-A12), los cuales han sido terminados con excelentes resultados para la construcción de las complejidades de la historia contemporánea a partir de fuentes orales. Por su parte, los proyectos Ruralidad y cambio sociocultural en las comunidades de la Cuenca del Río Jabonal de Javier Madrigal Córdoba (550-B7-263) y Reconstrucción de la memoria colectiva en las zonas de influencia de la Sede del Pacífico: Caso Angostura de Puntarenas 1975 de Kathia Cousin Brenes (550-B8-300), se encuentran en proceso de culminación.

6 Actualmente, la Universidad de Costa Rica posee trabajos finales de graduación que utilizaron fuentes orales, por ejemplo: La fiesta de la independencia en Costa Rica 1821-1921 (Díaz, 2001); Trayectorias ocupacionales de las familias de ex trabajadores bananeros en el Pacífico Sur de Costa Rica, durante 1949-2015 (Mena, 2017); En el fondo el olvido es un gran simulacro: violencia política en la postguerra costarricense (1948-1958) (Ugalde, 2017); Memorias de agricultura: despojos $y$ resistencias en el contexto de las transformaciones del Estado Desarrollista en el caso de la comunidad de Potrero Grande de Buenos Aires de Puntarenas 1963-1985 (Muñoz, 2018). 
(TCU). Posteriormente, los testimonios fueron cotejados con la historia que se encuentra registrada y cabe mencionar que podrían existir otras categorías que, por razones de espacio y tiempo, no se incluyen en este documento.

Los 3 referentes de este trabajo abarcan: la importancia de las historias de vida, la memoria e identidad colectivas $y$, por último, las trayectorias laborales.

\section{IMPORTANCIA DE LAS HISTORIAS DE VIDA}

Para autores como Lara, Marina, Macías y Camarena (2010), la pertinencia de las "historias de vida", dentro de los estudios cualitativos, implica mantener una escrupulosa metodología entre persona investigadora y protagonistas, en la que la primera está obligada a observar, escuchar, comparar y describir (Sanmartín, 2003), de una manera objetiva, los acontecimientos y vivencias contados por estos últimos.

En ese sentido, las "historias de vida" se basan en experiencias concretas del sujeto, de cómo interpreta el entorno que lo rodea. Tal como lo plantea Leonor Arfuch (2002), en las "historias de vida"7 se recupera la "voz del otro", cuando se produce la "democratización de la palabra" para dar paso al estudio de aquellas voces que siempre han estado, pero a las que muchas veces los discursos dominantes han invisibilizado.

Antes de continuar es necesario preguntarse ¿por qué es importante recuperar las historias de vida de estas personas adultas mayores

$7 \quad$ Para Denzin (1978), citado por Antonio Martín (1995), debe realizarse una diferenciación dentro del relato de vida e historia de vida (life history $y$ life story). El relato se refiere únicamente a la construcción biográfica, mientras que la historia de vida describe tanto la "historia de vida narrativa vital de una persona recogida por un investigador, como la versión elaborada a partir de dicha narrativa, más el conjunto de registros y entrevistas a personas del entorno social del sujeto biografiado, que permiten completar y validar el texto biográfico inicial" (Martín, 1995, p.47). Se aclara que ambas técnicas están contenidas en una metodología más amplia denominada método biográfico, en el cual emergen términos como: investigación etnográfica, estudio de casos, observación participante, entre otros (Sanz, 2005). ubicadas en los hogares de ancianos? Esto permite debatir cómo construyen estos grupos su pasado y, al mismo tiempo, cuáles son los efectos sociales de su construcción; así como, disertar sobre lo que no se haya estudiado.

La realidad de la región Pacífico Central, por supuesto, no es la misma realidad de otra región de Costa Rica. De acuerdo con Ricoeur (1999), Arfuch (2002), Portelli (2004), Halbwachs (2005), Ferraroti (2007), Kuri (2017) y Chen (2018), las historias narradas por los sujetos solo adquieren sentido si se parte de una identidad, es decir, de un grupo con características en común, un conjunto de prácticas sociales $y$ culturales de una región.

\section{MEMORIA E IDENTIDAD COLECTIVA}

La memoria es un sistema complejo en el que se reúnen muchos elementos. En este trabajo no se trata de historias o simples rememoraciones, sino más bien de establecer la relación entre memoria y la representación del pasado en las sociedades, mediante su construcción. La memoria individual se relaciona con recuerdos fragmentados de un individuo sobre un acontecimiento; investigadores como Manero y Soto (2005) especifican que toda memoria es constructora de la realidad social con elementos subjetivos producto de las propias percepciones de los individuos, sus argumentos o su visión de mundo. Por su parte, Luz Mary Arias y Oriester Abarca (2015) afirman que la "memoria no refleja el pasado, sino cómo se lo representa el presente" (p.2).

Rajchenberg y Héau-Lambert (2000) definen la memoria como el "conjunto de representaciones, imágenes, saberes teóricos y prácticos, comportamientos, actitudes [que] un grupo o sociedad acepta en nombre de la continuidad necesaria entre el pasado y el presente" (p.27). En otras palabras, siempre habrá una relación entre la memoria y los procesos sociales. Maurice Halbwachs (2005) advierte que toda memoria es un pensamiento social, dado que está influenciada por el contexto donde se desenvuelve en relaciones sociales, de poder, de conflicto y subjetividad, entre otras. Asimismo, este autor afirma que la memoria individual está íntimamente ligada a 
la memoria colectiva ${ }^{8}$; pero estas memorias individuales están enmarcadas socialmente dentro del paisaje del tiempo y fuera de él. Es decir, que los marcos sociales ${ }^{9}$ de la memoria pueden estar representados por el lenguaje, el tiempo $y$ el espacio en los que los individuos construyen y organizan sus recuerdos (Halbwachs, 1975).

Ignacio Dobles (2009), Alfonso Torres (2011) y Edith Kuri (2017) analizan que la memoria individual posee un nexo con la identidad, en la medida en que la identidad contiene un conjunto de rasgos o características que distinguen a las sociedades, de quiénes somos y quiénes son los otros. Elizabeth Jelin (2002) indica que la identidad se sostiene por medio de recuerdos y rememoraciones de algo propio del pasado en un conjunto de personas. Para reforzar esta idea, la autora explica que la memoria funciona como un mecanismo cultural para consolidar el sentido de pertenencia de grupos o comunidades. La historia de cada individuo posee elementos similares a otros que permiten la caracterización de una colectividad.

Tal como lo señala Teun Van Dijk (2000), la identidad puede ser social o personal. En la identidad social sucede una unión de la identidad de grupo con la ideología de este. En la identidad personal hay representaciones mentales que pueden ser personales o sociales. En las representaciones individuales, se agrupan las biografías y en las sociales, se agrupan creencias, símbolos, tradiciones, folclore, entre otros.

Carlos Sandoval (2002) sostiene que las identidades nacionales en Costa Rica forman parte de la propia subjetividad de las colectividades, es decir, son construidas entre diferencias $y$ desigualdades de estas mismas;

$8 \quad$ Para Halbwachs (2005), la memoria colectiva es una construcción que se produce por la relación entre el individuo y el grupo, que se integra en una experiencia. El objeto de estudio de este trabajo no es la memoria colectiva, por tanto, no se profundizará en este concepto.

$9 \quad$ En los cuadros sociales, el lenguaje es el medio por el cual el individuo transmite los recuerdos y los comunica a los demás, dentro de un marco espacio-temporal específico (Kuri, 2018). se asignan sentidos de pertenencia ${ }^{10}$ entre los individuos. Por consiguiente, la identidad es la conceptualización que tiene cada persona en relación con su individualidad y su pertenencia a otros grupos basados en las diferencias de las prácticas sociales y culturales.

\section{TRAYECTORIAS LABORALES}

Toda sociedad desarrolla un tipo específico de relaciones sociales para atender la actividad laboral o lo que, comúnmente, se denomina trabajo ${ }^{11}$. Por ende, por "trabajo" no se comprende como un simple empleo, sino más bien, la manera de transformar la comunidad; o un entramado complejo de relaciones entre individuo/sociedad. Desde allí, para Adam Smith (1776) el trabajo es presentado como una fuente de productividad; mientras que Joseph Schumpeter lo señala como la prosperidad de las organizaciones y la maximización de las habilidades del empresario (Oser y Blanchfield, 1980). No obstante, Elsa Santamaría (2011) advierte que los cambios y valoraciones del trabajo están relacionados con las subjetividades de cada individuo $y$ sus percepciones sobre las distintas condiciones laborales. De esta forma, la autora explica que estas subjetividades responden a prácticas sociales, las cuales dan sentido a lo que son o hacen las personas.

Por su parte, el término de trayectorias laborales es definido como las "posiciones sucesivas que las personas van ocupando en su trabajo a lo largo de sus vidas, durante un período de tiempo determinado" (Roberti, 2012, p. 272). Otro enfoque indica que analizar las trayectorias laborales "permite reconstruir el proceso

$\overline{10}$ Generalmente, este sentido de pertenencia se refiere a un elemento fundamental en la definición y cohesión de la identidad personal y cultural. Ejemplo: las percepciones, los deseos, las experiencias que se construyen a través de las prácticas cotidianas desarrolladas personalmente y luego, grupalmente. En otras palabras, la identificación de un individuo con un grupo social.

11 Para Santamaría (2011) "el trabajo es una actividad material y simbólica situada en un espaciotiempo concreto de la vida de las personas y una relación social que vincula a la persona con un entramado social más amplio" (p.23). 
de asignación de personas a posiciones sociales como un proceso relacionado con el tiempo de la vida de las personas, $y$ con una determinada perspectiva del tiempo histórico" (Buigués, Crocco y Navarro, 2012, p. 28).

En ese orden de ideas, estas investigaciones sobre trayectorias laborales consisten en determinar y analizar las posiciones sucesivas que los individuos van ocupando en diferentes relaciones de trabajo, durante su vida o por un determinado período de tiempo. Sin embargo, hay que aclarar que el presente estudio solo contempla la actividad laboral desempeñada por los participantes por más tiempo y también la más gustada, aunque es posible que una persona haya desempeñado más de un tipo de empleo a lo largo de su vida.

\section{RESULTADOS}

Esta investigación de campo se realizó con la participación de aquellas personas adultas mayores que recordaban sus historias de vida $y$ estuviesen interesadas en participar para narrarlas voluntariamente $y$, de esta manera, reconstruir esta memoria con entrevistas (24) de profundidad, durante los años 2015 y 2016. Los temas tratados fueron organizados según las categorías de investigación que funcionaron como marcos de referencia para recolectar la información, en un proceso de intercambio para comprender los sucesos narrados por las fuentes orales.

\section{EDAD DE LA PERSONA ADULTA MAYOR ENTREVISTADA}

Tal como lo plantea Alejandra Sanz (2003), la edad es un elemento que estratifica a las personas condicionando sus roles en las comunidades, así como, sus relaciones interpersonales y sus percepciones del mundo que los rodea. Esta investigación muestra que el 100\% de los participantes en la investigación son personas adultas mayores, esto es, personas de más de 65 años. En ese sentido, si la infancia es el período entre el nacimiento y el inicio de la pubertad (entre 0 y 10 a 14 años, generalmente) y el grupo, en general, contaba con una edad promedio de 70 años, quiere decir que se enmarca en el decenio de 1950, justo después de la fundación de la Segunda República en el siglo xx.

Sumado a esto, en el análisis histórico del investigador Carlos Sojo (2013) se explica que a partir del decenio de $1950^{12}$ del siglo Xx, el gobierno costarricense hacía innumerables esfuerzos por mejorar la calidad de vida de la ciudadanía costarricense.

\section{GÉNERO DE LAS PERSONAS ENTREVISTADAS}

En el cuadro 1, se muestra la distribución por género en la investigación.

CUADRO 1

GÉNERO DE PERSONAS ENTREVISTADAS $2015-2016$

\begin{tabular}{ccc}
\hline & ABSOLUTO & RELATIVO \\
\hline Hombre & 15 & $62 \%$ \\
Mujer & 9 & $38 \%$ \\
\hline TOTAL & 24 & $100 \%$ \\
\hline
\end{tabular}

Fuente: Elaboración propia con base en entrevistas.

En el cuadro 1, se observa claramente que esta población de personas adultas mayores estaba conformada en $62 \%$ por hombres y $38 \%$ de mujeres. Es importante considerar que estos participantes en la sociedad costarricense no representan una población económicamente activa (dentro de la lógica capitalista) y pertenecen a un grupo minoritario de la sociedad

12 La Segunda República y el Estado de Bienestar iniciaron en el decenio de 1950 en Costa Rica. Para muchos, dicha forma de Estado era una tendencia global del capitalismo desde finales del siglo XIX en Europa, que tuvo como hito las políticas impulsadas por Otto Von Bismarck en Alemania o el New Deal de Roosevelt, luego de 1929. Esta tendencia tiene su punto de inflexión en el decenio de 1970, cuando se empieza a desmantelar el Estado de Bienestar y globalmente, se empieza a producir un proceso gradual de aumento de las desigualdades. En Costa Rica, el movimiento obrero obtuvo grandes logros desde el decenio de 1920 y la Constitución Política de 1949 no fue sino una versión casi íntegra de la de 1871 . A este respecto, el mismo Rodrigo Facio afirmaba lo singular del caso de Costa Rica, pues hubo una guerra civil para luego mantener la misma Constitución. 
costarricense de personas adultas mayores que están alejadas de sus familias. Estudios estadísticos del Instituto Nacional de Estadística y Censos (INEC) del año 2017, afirman que Costa Rica presenta un total de 389840 personas mayores a 65 años, esto es un 7,9\% de la población total del país y, para el año 2019, la cifra podría haber aumentado.

\section{ESCOLARIDAD}

Costa Rica, como país latinoamericano, ha subvencionado la educación pública a lo largo de los años con resultados favorables en la población para el siglo XXI (Cuevas y Mora, 2013). Desde mediados del siglo xx, el país se dedicó a mejorar la calidad de vida de sus habitantes, disminuyendo la mortalidad infantil y el analfabetismo, pues extendió la educación, tanto primaria como secundaria, entre la población (Molina y Palmer, 2008). Sin embargo, no fue hasta el decenio de 1970, que se decretó la educación primaria como derecho universal $y$, a su vez, se reforzó la educación secundaria (Mesalles, 2012).

CUADRO 2

ESCOLARIDAD DE LAS FUENTES ORALES

\begin{tabular}{lcc}
\hline & ABSOLUTO & RELATIVO \\
\hline No lee, ni escribe & 6 & $25 \%$ \\
Primaria incompleta & 9 & $38 \%$ \\
Primaria completa & 7 & $27 \%$ \\
Secundaria incompleta & 1 & $5 \%$ \\
Secundaria completa & - & - \\
Educación Superior & 1 & $5 \%$ \\
\hline TOTAL & 24 & $100 \%$ \\
\hline
\end{tabular}

Fuente: Elaboración propia con base en entrevistas.

Al analizar el cuadro 2, en relación con la escolaridad, se evidencia que $38 \%$ de estas personas poseen educación primaria incompleta, mientras un $27 \%$ de los participantes posee primaria completa $y$ un $25 \%$ de ellos no sabe leer ni escribir. Asimismo, un 5\% posee secundaria incompleta y un 5\% de ellos asistió a la universidad.
Entre las razones que explican su situación de escolaridad, los entrevistados y las entrevistadas expresan que, debido a la pobreza de la familia, las deficiencias en los caminos y la lejanía del centro escolar, se les dificultaba presentarse a un centro educativo. Además, no existían los medios de transporte que existen actualmente. Asimismo, el subgrupo femenino indica que los padres de las niñas preferían que ellas, desde muy temprana edad, realizaran labores domésticas, lavando y planchando en la casa ${ }^{13}$.

Además, en el cuadro 2 hay un 4\% de esa población que no recuerda su escolaridad, en tanto que otro $4 \%$ recibió educación técnica en una escuela de mecanografía y otro $4 \%$ no completó la educación secundaria (solamente aprobó sétimo año).

En relación con las personas participantes que no recuerdan (4\%), cabe mencionar que, según Halbwachs (2005), se guardan los recuerdos que interesan o los que nos agradan, pues la memoria es selectiva. Portelli (2014) explica que existe una relación entre acontecimiento y subjetividad, pues nadie se acuerda de lo que pasó, si no le es importante. Siguiendo este análisis, Dobles (2009) plantea en su obra Memorias del dolor, que el "olvido" no es otra cosa que la "interrupción del relato" (p. 114).

\section{RELATOS DEL PAISAJE EN SU LUGAR DE INFANCIA}

En relación con el lugar donde vivieron su infancia, tal como se observa en el cuadro 3 , un $63 \%$ permaneció en la provincia de Puntarenas, en zonas como Esparza, Miramar, Santa

$13 \quad$ Lo anterior se justifica debido a que el país poseía la estructura de la sociedad patriarcal; es decir, que era una sociedad que puntualizaba relaciones de poder en prácticas cotidianas, con herencias simbólicas en la cimentación de masculinidades y feminidades. En otras palabras, en esa época se establecían conductas en función de su sexo biológico; por ese motivo, tal como lo plantean Villarreal (2001) y Chaves (2012), la mayoría de las veces, las relaciones de poder fueron presentadas en todos los ámbitos, como una subordinación entre diferencias de géneros. 
Elena, Tambor, Puntarenas centro y Barrio El Carmen. De ellos, 13\% afirma que estuvo en San José, $8 \%$ en Alajuela, $8 \%$ en Guanacaste y $8 \%$ no lo recuerda.

\section{CUADRO 3 \\ PAISAJE DEL LUGAR DONDE VIVIÓ SU INFANCIA}

\begin{tabular}{lcc}
\hline & ABSOLUTO & RELATIVO \\
\hline Puntarenas & 15 & $63 \%$ \\
San José & 3 & $13 \%$ \\
Guanacaste & 2 & $8 \%$ \\
Alajuela & 2 & $8 \%$ \\
No recuerda & 2 & $8 \%$ \\
\hline TOTAL & 24 & $100 \%$ \\
\hline
\end{tabular}

Fuente: Elaboración propia con base en entrevistas.

Ahora bien, estos relatos están principalmente centrados en las siguientes imágenes del paisaje, los cuales se crearon a partir de las entrevistas realizadas:

a) Al referirse a ciertos lugares de Puntarenas, como Esparza, se encuentra que existían muchos árboles de nances, había mucho ganado y era un poco más caliente en relación con otras localidades. Poseía muy pocas casas. Sus calles eran de piedra y era polvoriento. Necesitaba iluminación nocturna. Eso sí, para los testimonios, sus habitantes poseían muchos valores morales y amor al prójimo.

Por su parte, en Miramar existían muchos árboles y animales, las viviendas eran escasas. Se presentaban "temporales" de lluvia muy frecuentes. Para las personas entrevistadas, era un paisaje de campo, es decir, una comunidad rural, mientras que hoy la ciudad es más moderna. Aun así, el centro escolar quedaba muy lejos del pueblo.

En lugares como Santa Elena, se relata que el paisaje era muy rural, había poquitas viviendas y mucha lluvia que arruinaba a veces las cosechas de café en el invierno.

En la ciudad de Puntarenas, específicamente, en el Barrio El Cocal y Barrio El
Carmen, las calles eran en su mayoría de arena sin pavimento, había muchas casas viejas de madera, se vivía mucho de la pesca $^{14}$. Contaban con una mínima iluminación en las calles. Además, todo era muy seguro y tranquilo, había personas muy atentas.

b) En esa línea, 13\% de las fuentes orales indicó que San José era un lugar muy agradable y seguro. Contaba con muchos cafetales, cañales y pocas calles pavimentadas, también pasaba de repente "la cazadora" (autobús) para trasladarlos al centro de San José. Había muchos valores morales como respeto por la vida, por los animales, en fin, era un ambiente más sano que hoy.

c) Acerca de Guanacaste, su atención se centró en Bolsón de Santa Cruz, pues recuerdan que tenían malas vías de comunicación (carreteras) y la provincia, en general, estaba dedicada a la agricultura ${ }^{15}$, contrario a los tiempos actuales, en los cuales la actividad predominante es la ganadería.

d) Ahora bien, al referirse a la provincia de Alajuela, las personas recuerdan que existían muchos cafetales, cañales $y$ árboles de mango. Las calles estaban poco pavimentadas $y$ polvorientas, se describía como un lugar sano para vivir.

e) A su vez, $8 \%$ de la población no recuerda el lugar de su niñez.

De todo lo anterior, se puede concluir que el tiempo y el espacio representan elementos importantes por los cuales se construye la memoria de todo ser humano. En estas historias, se puede observar que las personas realizan un contraste entre el pasado y el presente. Evocan con orgullo que el pasado era un "tiempo mejor", refiriéndose a eventos significativos de

14 Actividad de formación identitaria en gran parte de la población (Chen, Cordero y Bartels, 2017).

15 De acuerdo con la historia y los planteamientos de Sergio Reuben (1982), Rovira (2000), Alejandro Abarca y Surayábi Ramírez (2016), durante el decenio de 1950 del siglo xx, un 55\% de la población activa costarricense estaba empleada en el sector agrícola por el modelo de desarrollo agroexportador. 
sus vidas en la infancia. Para esta investigación, estos sujetos reconstruyen su memoria con imágenes dentro de un proceso de cambio entre el ayer y el hoy. Aquí, se aplica la teoría de Jelin (2002), quien afirma que la identidad se sostiene de recuerdos en rememoraciones de algo propio del pasado entre un grupo de personas.

\section{TRAYECTORIA LABORAL DE LA PERSONA ENTREVISTADA}

En ese orden de ideas, en la rememoración subyace el carácter selectivo de la memoria, la discriminación de aquello que será representable o memorable y lo que se suprimirá o quedará fuera. Por esa razón, se estudiarán las trayectorias de las personas entrevistadas en sus más importantes momentos. A continuación, se presentan las siguientes subcategorías:

\subsection{ACTIVIDAD LABORAL REALIZADA POR MÁS TIEMPO}

Al analizar los resultados de la investigación, en cuanto a la actividad realizada por más tiempo en esta población, se conforma el cuadro 4.

CUADRO 4

ACTIVIDAD LABORAL REALIZADA POR MÁS TIEMPO

\begin{tabular}{lcc}
\hline OCUPACIÓN & ABSOLUTO & PORCENTAJE \\
\hline Peón agrícola & 7 & 29 \\
Soldador & 1 & 4 \\
Policía & 1 & 4 \\
Oficios domésticos $^{16}$ & 5 & 20 \\
Salonero $^{16}$ & 2 & 9 \\
Comerciante $_{\text {Chofer }}$ & 2 & 9 \\
Conserje & 1 & 4 \\
Maestro & 1 & 4 \\
Estibador & 1 & 4 \\
Operario & 1 & 4 \\
\hline TOTAL & 2 & 9 \\
\hline
\end{tabular}

Fuente: Elaboración propia con base en entrevistas.

16 Para la investigación debe interpretarse como el apego del individuo a una actividad laboral.
El cuadro 4 refleja que las actividades laborales realizadas por más tiempo fueron muy variadas; la más recurrente es la ocupación de péon agrícola, dado que $29 \%$ indicó haber trabajado en el agro, en esa modalidad. A su vez, la segunda actividad laboral está representada por oficios domésticos, con $20 \%$ del total de la población (quienes en este estudio eran las mujeres). Asimismo, le siguen las labores de comerciantes, operarios y saloneros con $9 \%$, el resto representa $4 \%$ del total en actividades como chofer, conserje, estibador, policía y maestro.

Además, el 100\% de los participantes indicó que los trabajos durante su vida fueron escasos. Asimismo, el 90\% especificó que el dinero que ganaban apenas les alcanzaba para subsistir con los gastos de la familia y solamente, un 10\% indicó que sus salarios no fueron tan bajos.

\subsection{ACTIVIDAD LABORAL FAVORITA}

Siguiendo el estudio, se encuentra el sentido de pertenencia ${ }^{17}$ dentro de su trayectoria laboral ${ }^{18}$; es decir, el trabajo que más les gustó desempeñar en su vida. En este caso, es pertinente lo que indicaron Manero y Soto (2005), pues se construye una realidad social con elementos de subjetividad en cada memoria de las personas participantes. A continuación, se presentan los siguientes resultados:

RODRIGO

Rodrigo nació en Miramar, Puntarenas y comenta que fue el menor de 6 hermanos. Su padre se desempeñó por mucho tiempo como peón de la Hacienda El Palmar, en Miramar,. Durante el decenio de 1960, Rodrigo laboró como boyero y lo hizo gran parte de su vida, tal como lo indica su testimonio:

Para mí, lo más importante era trabajar con madera y con bueyes. Ese es el trabajo

$17 \quad$ Para la investigación debe interpretarse como el apego del individuo a una actividad laboral.

18 Como dato aparte, en la investigación, el 25\% de esta población indica que comenzó a trabajar entre los 5 y 10 años. 
más importante, pero ahora no hay. El trabajo de los bueyes, los sustituyeron los tractores, las máquinas [...] Y después vinieron las sierras, era más liviano el trabajo. El de bueyes era carretear madera para los aserraderos. Pero iba disminuyendo el trabajo (comunicación personal, entrevistado nro. 12, febrero de 2015).

En el relato de Rodrigo hay toda una evocación a la idea de que el pasado era mejor, pues indica que el trabajo de los bueyes era muy importante para él, aunque eso significara faenas largas y pesadas de trabajo. Se presenta un nexo entre acontecimiento y subjetividad. Según Alessandro Portelli (2014), la fuente oral da un sentido al relato $y$ trata de mantener viva su memoria en sus puntos de vista, dentro de un proceso de cambio entre ese ayer $y$ hoy.

En el contexto histórico, tal como lo plantean los investigadores Luis Paulino Vargas (2003), Rodrigo Quesada (2008) y Fernando Bofanti (2015), dentro de las políticas públicas en el nuevo modelo de desarrollo ${ }^{19}$ en el decenio de 1970 del siglo Xx, las exportaciones tradicionales permitieron financiar la importación de maquinaria e insumos agrícolas que hicieron más fácil el trabajo en la agricultura, pero con un reducido valor agregado ${ }^{20}$.

$19 \quad$ Estos modelos de desarrollo se introdujeron en Costa Rica a inicios de 1843, con el modelo agroexportador; luego con el modelo de sustitución de importaciones, implementado a partir de 1948 y, finalmente, con la liberación económica en 1982; coexisten todos hoy "superponiéndose uno sobre otro" (Cousin, 2015). Sin embargo, en cuanto al modelo de sustitución de importaciones o desarrollista, ciertos autores como Villasuso (2000), Vargas (2003) y Sánchez (2004) afirman que fue desplegado más que todo en la mitad de los años del decenio de 1950 del siglo xx.

20 En los decenios de 1950, 1960 y 1970, el político José Figueres buscó (en opinión de Rafael Sánchez) consolidar un nuevo grupo dominante, con nuevas ideas de cambio y continuidad en la vida política y económica como un "transformismo no populista” (2004, p. 59). Se alcanzó a promover el crecimiento económico dentro de una dinámica de poder que consolidó el Estado costarricense y la economía desde 1960-1978. En contraste, el grupo de investigadores León et. ál.
Desde el contexto interno, de acuerdo con autores como Rodríguez (1993) y León, Aguilar, Chacón, Peters, Jara y Villalobos (2014), Costa Rica experimentó un dinamismo en su economía en el decenio de 1950, con el nuevo modelo de desarrollo de "sustitución de importaciones", pero también se modificó la composición del sector primario con la aparición de nuevos actores empresariales (cuadro 5).

CUADRO 5

EVOLUCIÓN DE LA POBLACIÓN RURAL

ACTIVIDADES AGRÍCOLAS Y CAMPESINAS COSTA RICA

(EN PORCENTAJES)

\begin{tabular}{lcccc}
\hline TIPO DE POBLACIÓN & 1950 & 1963 & 1973 & 1984 \\
\hline Población rural $^{21}$ & 66,5 & 65,54 & 59,39 & 55,51 \\
Población agrícola $^{22}$ & 54,72 & 47,20 & 35,49 & 30,11 \\
Población campesina & 28,35 & 22,31 & 14,16 & 13,27 \\
\hline
\end{tabular}

Fuente: Rodríguez, 1993, p.51.

Según el análisis del cuadro 5, tanto la población rural como la agrícola y la campesina fueron disminuyendo, lo cual coincide con la disminución porcentual de la población rural mundial, por la primacía del sector secundario sobre el primario. Aunado a esto, empresas dedicadas al comercio, industria y servicios comienzan a tener un papel importante en la economía de Costa Rica, por medio de las políticas públicas mediante la Ley de protección y Desarrollo Industrial nro. 2426 del año 1959; $y$ el agro, aunque era promovido por el gobierno, lo fue en menor escala (León, et. ál, 2014).

(2014) admiten que hubo, en esas épocas, un crecimiento, mas no desarrollo económico. La razón está en que, si bien es cierto, se deseaba reemplazar los bienes importados por las producciones locales en la economía, las materias primas y la tecnología debía importarse, persistiendo así la dependencia de Costa Rica hacia las naciones desarrolladas.

21 Se refiere a un grupo de personas que viven en zonas rurales, independientemente de sus actividades.

22 Son un conjunto de personas que se dedican a actividades agropecuarias. 
Actualmente, en Costa Rica, es el sector terciario el que domina la economía local.

\section{ÉDGAR}

Édgar es un adulto mayor proveniente de Zapotal de Miramar de Puntarenas, quien fue el menor de 9 hermanos $y$, además, inició su trayectoria laboral a la edad de 7 años, "chapeando lotes", o sea, cortando zacate. A continuación, se describe la vivencia de este adulto mayor:

Primero, conseguí trabajo cuidando una cantina, me habló un señor que tenía una cantina, para que cuidara la cantina [...] ahí por unos robos que hubieron, $y$ yo [...] di con los robos. Entonces un maestro se le metieron y le robaron todo el equipo [que tenía] ... Me puse a la pista, $y$ di con los robos, entonces ese maestro vino e hizo una carta y la mandó a San José, recomendándome como buena autoridad que era, y ya después de todo me pasaron de policía, a la guardia de Puerto Cortés. [...] En la ley estuve trabajando como unos 2 o 3 años, figúrese usted que para la [guardia nacional].

Bueno usted está nuevillo, usted no estaba cuando ese tiempo, cuando para las elecciones de Figueres, Figueres el viejo, el reformista. Exactamente el papá de Figueres [Olsen] y entonces de ahí nos tocó ir a sacar precaristas en la Zona Sur, y no me gustó el toque de los precaristas esos que fuimos a sacar, porque yo me puse a pensar "los sacamos con engaños". Porque ya habían entrado varias autoridades a sacarlos y no habían podido, entonces vinieron $y$ nos hablaron a nosotros que trabajábamos en la guardia de Puerto Cortés y ya nos reunimos en Villa Neilly. De ahí nos fuimos un día, iban unos buses llenos de gente de autoridades y llegamos donde los precaristas $y$ a puros engaños $y$ mentiras los sacamos de esa tierra. ¿Quiénes eran? Solamente campesinos... (comunicación personal, entrevistado nro. 10, febrero de 2015).
En la reconstrucción de su memoria permanece un recuerdo muy particular, quizá de dolor, que no puede cicatrizar porque permanece abierto y lo recuerda como si fuera ayer, relacionado con el desalojo de estas personas. Su historia de vida expone que, durante la segunda administración de José Figueres (1970-1974), aparentemente, estos denominados "precaristas" eran -en muchos casos - campesinos o agricultores asentados en terrenos en los cuales no tenían títulos de propiedad. Según Carlos Rodríguez (1993), las invasiones de este tipo obligaron $^{23}$ al gobierno a intervenir dentro de

$23 \quad$ Se debe indicar que la zona del Pacífico Sur estuvo alejada de los intereses del Estado costarricense desde la época colonial. Aunado a esto, según el historiador Juan José Marín la "parte sur del Pacífico pasó a ser, en el mejor de los casos, una zona subvalorada, la tónica fue considerar a este territorio como un área vacía, sin mucho potencial" (Marín, 2009). Como en los años veinte decae la producción de banano en las plantaciones del Caribe, el Estado se preocupa y realiza un informe, con fecha de 1930, de Mariano Montealegre hacia al presidente Cleto González, en el cual asegura la posibilidad de que el terreno del Pacífico Sur era apto para el cultivo del banano. De esta manera, finalizando el decenio de 1930, la actividad bananera fue una realidad (Arias, 2008 y Royo, 2008) en el sur del país.

De acuerdo con lo anterior, la empresa United Fruit Company (UFCo) decidió trasladarse al Pacífico Sur para iniciar la época del cultivo del banano, más que todo a partir de 1935, pues la actividad en la Zona del Caribe se había reducido por el agotamiento de suelos y amenazas de algunas plagas relacionadas con el banano que limitaban las exportaciones (Royo, 2008). En 1935, la UFCo adquirió el control de la Pirris Farm \&Trading Company, así como, el monopolio de facto en el Pacífico (Royo, 2004).Tal y como había ocurrido en la zona caribeña, la Zona Sur floreció en cuanto a bienes y servicios, pero los cantones de Osa, Golfito y Corredores eran dependientes de la producción bananera, sin mediar otra actividad económica relevante en esa población y, además, prevalecían algunas malas comunicaciones por vía marítima o terrestre (Arias, 2008).

Aunado a esto, a partir de 1960, con la construcción de la Carretera Interamericana Sur, esta región tuvo un contacto con otros lugares del país. Ahora bien, en ese marco, en el impacto social, la mano de obra cesante de la bananera $y$ el cambio del cultivo por palma africana, produjo que muchos trabajadores quedaran sin sustento 
una política agresiva de compra de tierra sin ninguna planificación. Así que, de algún modo, el relato de vida de Édgar como guardia nacional, llegó a verificar lo que la historia oficial someramente había descrito, esto es, que hubo desalojos por parte de las autoridades a unos "precaristas" en Puerto Cortés, los cuales eran campesinos.

Para reforzar lo anterior, por las políticas públicas de reforma agraria en Osa ${ }^{24}$, este cantón logra, entre 1963 y 1973, sustituir las siembras de banano por arroz, maíz, entre otros (Meza y Smith, 1997), gracias al apoyo del Estado. Es contradictorio pues, por un lado, el gobierno realiza desalojos de personas que no poseen títulos de propiedad $y$, por otro lado, los promovía en siembras de otros productos que no fueran banano.

\section{MARÍA Y JUAN}

María proviene de Abangares de Guanacaste, fue la mayor de 16 hermanos. Su padre era de origen turco ${ }^{25}$ y su madre costarricense.

$y$ optaran por ir "tomando terrenos tanto en las inmediaciones de las fincas, como en terrenos de la compañía" (Rodríguez, 1993, p. 70).

Otro aspecto a mencionar es que se produjeron tomas de tierra por parte de campesinos en los años 60, en lugares como Golfito y Corredores, en una gran mayoría de terrenos (Rodríguez, 1993). Como un dato aparte, para el año 1984, la Compañía Bananera abandonó la Zona Sur, cerrando un ciclo de cincuenta años de explotación bananera en el Pacífico costarricense (Royo, 2004).

En 1962, en Costa Rica se creó el Instituto de Tierras y Colonización (ITCo, después IDA en 1982) para resolver los conflictos de tierra a nivel general, con el fin de realizar una reforma agraria $y$ atenuar en el Sur la crisis bananera (Arias, 2008 y Royo, 2008). Sin embargo, para el historiador Dennis Arias, la intervención del IDA en el cantón de Osa produjo una "descampesinización paralela a la recampesinización que intentaba consolidar. El IDA recurrió a la compra de tierras invadidas sin ninguna estrategia planificadora" (Arias, 2008, p. 30).

El Estado, en esta reforma agraria, lejos de desaparecer los problemas agrarios, lo que hizo fue preservar el statu quo imperante dentro de una reforma marginal. Esto representó los intereses de las clases políticas dominantes y dejó de lado a los campesinos sin tierra (Royo, 2008).

Así se denominaba en Costa Rica, al menos durante la primera mitad del siglo $\mathrm{xx}$, a los libaneses que habían huido de los horrores de la I Guerra
Además, desde pequeña residió en Puntarenas centro y empezó a trabajar a los 17 años en oficios domésticos en casas de habitación, debido a sus necesidades económicas. Sin embargo, dentro de su trayectoria laboral, la actividad que más recuerda $y$, por ende, es la que genera mayor sentido de pertenencia es la siguiente:

Yo he vivido todo el tiempo sola, trabajaba en casas y después como yo padecía de los huesos dejé el trabajo de casas, [pues] no le tenían seguros, ni nada [...] — Diay una vecina me dijo: a usted la tratan mal en la casa porque no busca trabajo, diay como nunca he trabajado $y$ vengo yo le hice caso y me fui a una pulpería que quedaba cerca de Frigoríficos, fui y pedí trabajo [...] topé con suerte, estaba el jefe que era un gringo - ¿Qué se le ofrece? - Me hace el favor y me da trabajo - Como no, vaya para que le tomen las medidas del uniforme, mañana a las 9 está aquí, $y$ de verdad, así fue [...] Entonces me dediqué a [trabajar en] las camaroneras. Primero Frigoríficos, después Don Rodrigo Calvo, los Guevara, Borda Azul y otras tres más que no recuerdo. [Entre todos los trabajos] yo digo que el más importante era pelar [camarones], porque ganaba uno más [dinero] (comunicación personal, entrevistada nro. 17, enero de 2016).

Juan es un adulto mayor, quien tenía 8 hermanos y empezó su trayectoria laboral trabajando para la Compañía Bananera en la Zona Sur, a los 14 años. Sin embargo, al referirse al trabajo más gustado, expone lo siguiente:

El trabajo que más me gustó fue la camaronera, llamada Compañía Industrial de Mariscos, propiedad de don Rodrigo Calvo, ubicada en Las Playitas ${ }^{26}$,

Mundial. Eran libaneses, católicos en su mayoría. También se les denominaba "sirios". Desde esa línea, Puntarenas tuvo una importante colonia de "turcos", como las familias Nicolás, Tabash, Morún, entre otras.

26 Es nombre propio. A principios del siglo xx a este sector de la ciudad de Puntarenas se le conocía 
exactamente en el "Rastro" 27. Eso fue en 1962. Diay, calculo que había entre 12 o 15 camaroneras en la zona y se exportaba camarón de todos tamaños, algunas eran propiedad de gringos.

Era un trabajo muy diferente a la bananera, llegaban lanchas a cada rato. Había mucha producción, era una empresa ordenada, manejaba como sesenta empleados, entre ellos 3 peones y el resto mujeres desde 15 (con permiso) hasta los 65 años.

Primero yo comencé de planillero, luego se fue mi jefe y como yo tenía habilidades para sumar y buena memoria [tenía tercer año de colegio] me pusieron como jefe de planta $y$ de personal. -Yo mangoneaba todo el personal- [...] trabajé como 10 años y luego vino Carlos Alberto Delgado, y me ofreció un trabajo cerca. Me fui, pero sentí que metí la pata. Allí el trabajo no fue tan bueno.

Meditando, en la camaronera [Calvo] el trabajo era duro, pues no había cámaras de refrigeración, había que traer el hielo $y$ para poner hielo a los productos de manera picada. Además, de vez en cuando me pedían cuenta si alguna empleada faltaba a trabajar.

Luego recordando el trabajo que no me gustó fue el de Fertica en los setenta. Viera como afectaba los pulmones, allí salió más de uno con los pulmones malos o enfermos. Porque uno inhalaba eso, aunque yo no trabaja en la planta, yo trabajaba en la parte baja, pero, salían los gases poco a poco, por dicha no me agarró nada. En Fertica era muy serio todo, tenía mucha tecnología, yo tenía

como Plaza González Víquez. No se debe confundir con la plaza josefina.

Donde actualmente se ubican las oficinas del INAmU en la ciudad de Puntarenas. teléfono, calculadora y los beneficios eran buenos. Donde Calvo las máquinas para sacar cuentas era una calculadora Monroe. Bueno diay, un tiro me hicieron una prueba contable en la Calvo y dijo don Rodrigo: - Este hombre es un balazo (comunicación personal, entrevistado nro. 22 , febrero de 2016).

Según Halbwachs (1975), los recuerdos que guardamos de cada época en nuestra vida son reproducidos por la memoria, que hace que el pasado permanezca. De los anteriores testimonios se puede indicar que ambos casos evocan un pasado como un tiempo mejor. En ellos, la memoria ofrece la ilusión de indicar que lo que ha pasado no ha desaparecido, dado que se puede revivir a través del recuerdo.

Ahora bien, históricamente, a principios del decenio de 1960, en la ciudad de Puntarenas - como puerto - se dio un auge de desarrollo en la industria pesquera, acrecentando los niveles de producción, es decir, se aumentaron las flotas pesqueras, se introdujo una mejor tecnología y una mayor especialización de la fuerza de trabajo. De esta manera, se dió un crecimiento de la infraestructura de grandes empresas productoras, procesadoras, empacadoras y exportadoras que se instauraron en el puerto. Al respecto, Elizondo afirma que “... a finales de los años setenta había en Puntarenas 15 empresas camaroneras que entre ellas exportaban un $80 \%$ del producto elaborado, principalmente, al mercado norteamericano" (Elizondo, 2005, p. 57).

Según las personas entrevistadas, también la mayoría de esas empresas camaroneras pertenecían a capital extranjero. En ambas entrevistas, se visualiza en su percepción un sentido de pertenencia, tanto geográficamente como de grupo social en el trabajo de proceso de camarón; asimismo, el recuerdo más fuerte en su memoria está representado por el florecimiento económico de la zona con grandes empresas extranjeras y locales.

\section{SANTOS}

Santos es un adulto mayor que nació en Puntarenas. A los 14 años se fue a la Zona Sur 
con sus padres en busca de oportunidades laborales. Allí estaban ubicados primos, tíos y otros familiares. El trabajo que más le gustó fue en la Compañía Bananera, en el Pacífico Sur.

Yo trabajé en muchos trabajos, pero el trabajo que más me gustó fue zanjeando en la Compañía Bananera en el Sur. Pienso que - patrón como ése cuesta mucho que haiga habido-, no le robaban un cinco, si le robaban en el siguiente cheque se lo devolvían.

Lo malo de esa empresa es que cuando empecé a trabajar con ellos, no le tenían protección al trabajador como guantes, máscaras, cascos, totalmente el trabajador estaba desprotegido contra todo. 0 sea, en mi tiempo, no había esa protección al trabajador.

Aunque estuve en una huelga bananera, pero terminó cuando nos mataron a un compañero, por los años sesenta. La huelga se hizo por lo que estamos hablando ahorita, el trabajador estaba muy mal pagado, las remuneraciones $y$ los trabajos con insecticidas. [...] Es que como te dijera yo, algunos departamentos muy buenos, otros malos, [aunque] yo no me quejaba. - Porque yo definitivamente volando pala, ganaba mucha plata, tantísimo dinero ganaba- Pero los pobres que trabajaban en la agricultura cortando banano, conchando ${ }^{28}, y$ acarreando ${ }^{29}$ estaban mal. [...] no se sabe quién mató al compañero en la huelga, en esas cosas no se sabe, eso fue en la Zona Sur. Después de la huelga me vine para Limón [1962-1963], luego regresé otra vez a la bananera en el Sur hasta 1975, fecha que terminé mi relación laboral con ellos.

Transportaban el banano desde que es cortado hasta el carro del ferrocarril.

Transportaban el banano desde el carro hasta donde empacan el producto.
-Yo en la bananera adquirí mucho conocimiento, me ascendieron con lo que fui aprendiendo-.

Vuelvo a repetir el trabajo que más me gustó, fue este, zanjeando. ¿Por qué? era un trabajo decente, se llenaba de barro, pero no andaba con el peligro de cortarse, de que lo picara una culebra, estaba en lo limpio usted trabajando. [...] Ganaba 600 o 700 colones por quincena.

[Agregando que] Después de la lucha sindical, la bananera le dio casa, luz, hospital, doctor [...] porque antes si nos picaba una culebra hacían al trabajador a un lado, para que simplemente muriera, porque no se atendía con un doctor o medicamentos.

Además, un compañero que no sabía leer ni escribir le hizo una canción a la bananera: la compañía no nos cuida, porque no hay doctor o hospital, si nos pica una culebra, aquí nos entierran por falta de doctor o hospital (comunicación personal, entrevistado nro. 21, febrero de 2016).

De lo anterior, se desprende que la memoria individual de este adulto mayor se encuentra enmarcada en el tiempo y espacio que estuvo la Compañía Bananera en el Pacífico Sur. A pesar de que existían aspectos negativos en su narrativa, se destacan los "beneficios" de trabajar con la empresa: salarios más altos, asignación de vivienda en la cual la empresa les brindaba electricidad y agua potable, entre otros.

Este participante, en su relato, muestra otra versión a la que predomina en el más célebre de los textos, Mamita Yunai (1941) de Carlos Luis Fallas, sobre las denuncias de las injusticias sociales en las relaciones obreropatronales en las plantaciones de banano de la United Fruit Company. Es decir, el entrevistado afirma que la compañía explotó laboralmente a los trabajadores encargados de la corta, 
transporte y acarreo del banano; por el contrario, el trato era diferente con los zanjeros.

Lo anterior justifica la teoría de Nikolas Rose (1998), quien indica que las memorias son construidas por medio de las prácticas sociales; por ese motivo, Santos añora el pasado, para él un tiempo mejor cuando fue bien remunerado, según su criterio; pero su memoria no recuerda para sí mismo, la situación laboral en la United Fruit Company. Por otro lado, dentro de su componente identitario, su percepción lo induce a reconocer que es parte de un grupo social: el de los extrabajadores bananeros.

\section{CRISTÓBAL}

Cristóbal, quien fue maestro, nació en Esparza, Puntarenas. Fue el cuarto de diez hermanos. Comenta que, entre sus habilidades, lleva una gran pasión de componer poesía y así presenta con orgullo, su testimonio:

Los primeros dos libros los tiré y esos se fueron a la venta, poesía "Monge del Valle" creo que ya murió... la última vez que fui a San José lo vi muy fatal. Él sacó dos casetes de las poesías mías, uno con 20 poesías y otro con 18 , esta yo la escribí, pero mejor dicho esta "Añorando mi infancia" porque pongamos el poeta no nace, lo hacen, pero uno se afina en el colegio y la universidad....

"Añorando mi infancia" (Recita)

Mi casita agujereada,

Así siempre la llamaba,

Porque en noches de invierno,

La lluvia nos bañaba.

Yo recuerdo que sufrimos

Pero, más sufrió mi madre,

Luchando por nosotros,

Como madre y como padre.

Porque un padre responsable,

Nosotros no tuvimos,

Y por la que hoy está en el cielo,

Por ella es que vivimos.

Mi casita agujereada,

Se asemejaba a un cedazo,
Cada vez que la recuerdo,

Mi corazón, se hace pedazos"

(Comunicación personal, entrevistado nro. 20, febrero de 2016).

De la anterior composición realizada por Cristóbal, se analizan en este contexto: su historia basada en experiencias sobre las relaciones familiares, la pobreza en la cual vivió su familia de origen puntarenense $y$ la añoranza de un padre ausente. Hay una memoria de dolor en su narración, la cual devela carencias de un hogar con una figura paterna ausente. Asimismo, expone su punto de vista sobre la construcción del término pobreza como "limitaciones económicas".

Existen diversos significados que se construyen respecto al término pobreza, el primero, señala que esta "puede ser vista en términos relativos, cuando es definida en relación con otras situaciones y contextos sociales organizados en torno a la satisfacción de las necesidades, $y$ estilos de vida, con los que es confrontada y diferenciada" (Salles, 1999, p.48). El segundo término se "refiere a la subsistencia por debajo de un mínimo de condiciones de vida, socialmente aceptados que usualmente son establecidas con base a requerimientos nutricionales y otros bienes esenciales" (Aguado y Osorio, 2006, p. 28-29).

Lo cierto es que, aunque existen muchas definiciones, en la memoria de Cristóbal esta fue percibida como carencia de bienes. Asimismo, se indica que en la época de infancia de este participante, esto es, en el decenio de 1950, más del $50 \%$ de la población de Costa Rica era pobre y las sociedades estaban marcadas por una diferenciación social impulsada por la concentración de la riqueza (Sojo, 2013).

\section{CONCLUSIONES}

Para lograr un espacio de reflexión y crítica de los problemas que aquejan a las sociedades latinoamericanas, es indispensable recapacitar sobre las valiosas contribuciones de personas que fueron sujetos de la historia de Centroamérica y de Costa Rica. Para este caso, los grupos residentes de los hogares de ancianos de Miramar y Esparza, invitan a rescatar la 
historia mediante sus experiencias vividas. Se expone, sucintamente, lo más sobresaliente de esta investigación:

$\diamond \quad$ Las personas entrevistadas interpretan el pasado desde procesos $y$ prácticas sociales que asientan y moldean su subjetividad en torno a sus propias percepciones, ideas o creencias.

$\diamond \quad$ La totalidad de las fuentes orales posee una edad de más de 65 años. Por tanto, comparten una infancia vivida en el decenio de 1950 del siglo XX.

$\diamond \quad$ En términos de género, $62 \%$ de los testimonios son de hombres y $38 \%$ son de mujeres.

$\diamond \quad$ En el estudio se evidencia que la mayoría, o un equivalente a $38 \%$ de estas personas adultas mayores, posee educación primaria incompleta. Se observa que solo $27 \%$ de los participantes posee primaria completa y $25 \%$ de ellos no sabe leer ni escribir. Un porcentaje muy pequeño tiene mayor escolaridad, un $5 \%$ de ellos que posee secundaria incompleta $y$, por último, $5 \%$ de ellos asistió a la universidad. De acuerdo con este estudio, muchos no pudieron asistir a la escuela e incluso no lograron saber leer o escribir por las condiciones del entorno: malos caminos, centros alejados de las viviendas, escasos recursos económicos, entre otros.

$\diamond \quad$ Entre la población estudiada existe una tendencia a evocar al pasado como un tiempo mejor, referido a eventos significativos de sus vidas. Desde esa línea, la fuente oral reconstruye en su mayoría, la memoria con imágenes dentro de un proceso de cambio de ayer y hoy.

$\diamond \quad$ La actividad laboral en la cual se desempeñaron por más tiempo fue la agrícola, con un $29 \%$, principalmente como peones. En segundo lugar, un $20 \%$ se desempeñó en oficios domésticos; $y$ en tercero, se encuentran los comerciantes, operarios y saloneros que conforman un $9 \%$. Finalmente, un $4 \%$ estuvo constituido por actividades como chofer, conserje, estibador, policía y maestro. No obstante, resulta interesante que no se presente la pesca artesanal entre esas actividades laborales desempeñadas por más tiempo. Pues históricamente, la pesca es una actividad practicada en diferentes zonas marítimas costeras caribeñas o pacíficas de Costa Rica. Posee gran importancia social y económica para el país. Precisamente, desde la época de los años sesenta del siglo Xx, el Golfo de Nicoya fue el escenario pesquero en el cual se extraían los mayores recursos pesqueros del territorio nacional (Elizondo, 2005). Además, tal como lo plantean las investigadoras Chan y Del Río (2004), la actividad pesquera es una actividad cultural dentro de un cúmulo de "conocimientos que para algunos se han transmitido, de padres a hijos, ya sea que la dedicación a la pesca sea parcial o total. Para otros, como un saber aprendido ya de adultos y sin tradición familiar" (p.181). Lo anterior, según las autoras, es aprendido mediante la oralidad o la observación.

$\diamond \quad$ La historia de vida no solo expone su testimonio, sino que se mantienen recuerdos sobre acontecimientos históricos, por ejemplo, en cuanto al desalojo de "precaristas" por parte del Estado en la administración de José Figueres Ferrer narrada por Édgar. Así también, Rodrigo enfatiza el cambio de tecnología que vivió la agricultura en la época del decenio de 1960, en el modelo desarrollista o de sustitución de importaciones. En esa línea, María y Juan recuerdan la cantidad de trabajo y el auge económico que trajeron empresas camaroneras, tanto extranjeras como locales, a la ciudad de Puntarenas, a mediados de la década de 1970 .

$\diamond \quad$ Ahora bien, los marcos sociales de la memoria de estos participantes están representados, principalmente, en los decenios de 1950, 1960 y 1970. En ese lapso, las transformaciones económicas y empresariales de Costa Rica correspondieron a los "años dorados de los cincuenta $y$ sesenta" en cuanto al crecimiento 
de la industria, el comercio y otras actividades económicas, con miras a mejorar la tecnología y generar empleo. Así, también el espacio está caracterizado por lugares variados como: Puntarenas Centro, Miramar, Esparza, Alajuela, San José, Guanacaste, e inclusive, otros lugares de la zona bananera. Además, la memoria de Santos, se encuentra enmarcada en el tiempo y espacio que estuvo la Compañía Bananera en el Pacífico Sur. En el caso de Édgar, quien especificó recordar con cariño el decenio de los años de 1970, se debe analizar que el modelo de desarrollo sustitución de importaciones entraba en crisis y se agotaba. Por tanto, empezaban a tomar fuerza en Costa Rica, los conflictos de tenencia de la tierra, por la lucha de los derechos y crecían las desigualdades entre las distintas clases sociales, pues se había agotado la frontera agrícola.

$\diamond \quad$ Precisamente, en la historia de vida de Cristóbal, la memoria revela una construcción del término de pobreza como una privación de bienes junto con la ausencia del padre, desde un aspecto descriptivo; más que explicativo. En su testimonio, se exploran así las dimensiones espaciales y simbólicas de la pobreza a partir de esta narrativa, pues sus percepciones están relacionadas con el lugar donde vivió y la manera como son visualizados los "pobres".

$\diamond \quad$ Si bien, la construcción de la identidad, se refuerza con los recuerdos de rememoraciones de algo propio del pasado dentro de un grupo social, para Santos, su percepción lo induce a reconocer que es parte de un grupo social: el de los extrabajadores bananeros. En el relato de María y Juan, se analiza un sentido de pertenencia tanto geográfica como socialmente en el trabajo de empresas pesqueras de la ciudad de Puntarenas. Asimismo, en los relatos del paisaje en su lugar de infancia, un gran número de los participantes de localidades de Puntarenas (63\%), recuerda la pesca como una actividad importante para el puerto, constituyendo esto un elemento identitario de la comunidad.

$\diamond \quad$ Para terminar, el legado de la fuente oral para la historia es indudable. Con otros trabajos similares de investigación, a futuro, podría realizarse un archivo de memorias de gran importancia tanto para la Universidad de Costa Rica-Sede del Pacífico como para la sociedad porteña. También podrían promoverse nuevas investigaciones cualitativas de temas no estudiados en la zona de influencia de la Sede.

\section{REFERENCIAS}

Abarca, A. y Ramírez S. (2016). Estudio del crecimiento económico costarricense 19602014. San José: Observatorio de Desarrollo de la Universidad de Costa Rica.

Aguado, F. y Osorio, A. (2006). Percepción subjetiva de los pobres: una alternativa a la medición de la pobreza. Revista de Psicología: Panorama, (15).

Arfuch, L. (2002). El espacio biográfico. Dilemas de la subjetividad contemporánea. Distrito Federal: Editores FCE.

Arias, D. (2008). Aproximación al estudio del cantón de Osa 1914-1900. Revista Electrónica de Historia Universidad de Costa Rica, 2 (2).

Arias, L. y Abarca O. (2015). La Ciudad de Puntarenas y sus vehículos de memoria. Algunas implicaciones de teoría emergente. Revista Intersedes, XVI (34).

Beltramino, F. (2007). Metodologías cualitativas, modelos y procedimientos de análisis. Buenos Aires: Editorial Biblos.

Bermúdez, N. y Rodríguez, M. (2009). La fuente oral en la reconstrucción de la memoria histórica:su aporte al documental "Memorias del Zulia Petrolero". Revista de Ciencias Sociales, XV (2), 317-328.

Bertaux, D. (2005). Los relatos de vida. Barcelona: Ediciones Bellaerra.

Bofanti, F. (2015). Análisis del modelo de industrialización por sustitución de importaciones en América Latina y en Argentina. Una mirada hacia la realidad industrial 
de Argentina. Revista Geográfica Digital, 24, 6-7.

Buigués, M., Crocco, E. y Navarro, M. (2013). Trayectorias laborales estancadas $y$ acumulativas en jóvenes urbanos Sanjuaninos. Un estudio de caso. Revista IISE , 5 (5).

Chang, G. y Del Río, x. (2004). Léxico de la pesca artesanal puntarenense en el Golfo de Nicoya una aproximación etnográficosemántica en Chomes, Costa de pájaros, Isla Chira y Puntarenas Centro. Káñina Revista de Artes y Letras, xxviII (2). Universidad de Costa Rica, pp. 179-190.

Chaves, A. (2012). Masculinidad y feminidad ¿de qué estamos hablando? Revista Educare, 16, 5-13.

Chen, S. (junio-noviembre, 2018). Los inmigrantes chinos y sus descendientes, una mirada desde los relatos de vida. Revista Estudios (36).

Chen, S., Cordero A. y Bartels, J. (2017). Relatos del paisaje de Puntarenas. San José: SIEDIN.

Cousin, K. (2015). Estudio de la evolución histórico económica de las pymes en Costa Rica (1950-2013). (Tesis de Doctorado en Estudios de la Sociedad y la Cultura). Universidad de Costa Rica, San José, Costa Rica.

Cuevas, R. y Mora A. (2013). Vendiendo las joyas de la abuela. San José: Editorial EUNED.

Díaz, D. (2001). La fiesta de la independencia en Costa Rica 1821-1921. (Tesis de postgrado de Historia de la Escuela de Historia). Universidad de Costa Rica, San José, Costa Rica.

Díaz, D. (2006). Memoria colectiva y ceremonias conmemorativas. Diálogos, 7(2).

Dobles, I. (2009). Memorias del dolor: consideraciones acerca de las comisiones de la Verdad en América Latina. San José: Editorial Arlequín.

Elizondo, C. (2013). Por eso estamos como estamos. Distrito Federal, México: Editorial Debolsillo.

Elizondo, S. (2005). Pesca y procesos de trabajo: el caso de pescadores de Isla
Caballo y Golfo de Nicoya. (Tesis de Licenciatura en Sociología), Universidad de Costa Rica.

Fallas, C. (1941). Mamita Yunai. San José, Costa Rica: Editorial Costa Rica.

Ferraroti, F. (mayo-agosto 2007). Las Historias de Vida como método. Revista de Ciencias Sociales (44), Universidad Autónoma de México.

García B. y Sepúlveda, J. (enero-abril, 1985). La historia oral en América Latina. Revista Secuencia,(1), 162-176.

García, K. (2007). El Trabajo Comunal en la Universidad de Costa Rica: Caso Gestión ambiental en Puntarenas. Revista de Ciencias Sociales, Universidad de Costa Rica, iii-iv (117-118), 211-223.

Halbwachs, (2005). La Memoria colectiva. Zaragoza, España: Presas Universitarias de Zaragoza.

Halbwachs, (2008). Una visión clásica y actual de la ideación conceptual de la sociología. El proyecto de una memoria colectiva y su radicación en el espacio. Anthropos, 218, 3-15.

Halbwachs, M. (1975). Les cadres sociaux de la Memoire. New York: University of Chicago Press.

Instituto Nacional de Estadística y Censos (INEC). (2017). Infografía del adulto mayor. San José: Instituto Nacional de Estadística y Censos.

Jelin, E. (2002). Los trabajos de la memoria: memoria de represión. Madrid: Editorial Siglo XXI.

Kuri, E. (2017). La construcción social de la memoria en el espacio: una aproximación sociológica. Universidad Autónoma de México, Censo Peninsular en Humanidades y Ciencias Sociales. Revista Península, XII (1), 9-30.

Kuri, E. (enero-junio,2018). Sentido, prácticas sociales y conflicto: la construcción social y política de la memoria. Revista de Ciencias Sociales, Universidad Iberoamericana, (25), 2018.

Lara, M., Marina, A., Macías, F. y Camarena, M. (2010). Los oficios del historiador: Taller y prácticas de la Historia Oral. 
Guanajuato, México: Universidad de Guanajuato.

León, J., Aguilar, J., Chacón, M., Peters, G., Jara, A. y Villalobos, M.L. (2014). Crecimiento y politicas económicas. San José, Costa Rica: Editorial Universidad de Costa Rica.

Ley de Protección y Desarrollo Industrial nro. 2426. (3 de septiembre, 1959). La Gaceta, Costa Rica.

Ley Integral para la persona adulta mayor y su reglamento nro. 6739. (28 de abril de 1982). La Gaceta, Costa Rica.

Manero, R. y Soto, A. (enero-junio,2005). Memoria colectiva y procesos sociales. Revista de Enseñanza e Investigación en Psicología, 10 (1), 171-189.

Marín, J. (2009). Procesos de desigualdad en el Pacífico. Una propuesta interpretativa (1850-1900). En O. Abarca; J. Bartels; S. Chen, y J.J. Marín (Eds.), Poder, colonización y arquitectura: región del Pacífico costarricense 1780-2000. San José: Centro de Investigaciones Históricas de América Central.

Martín, A. (1995). Fundamentación teórica y uso de las historias y relatos de vida, como técnica de investigación en Pedagogía Social, Aula, 7, 41-60.

Mena, F. (2017). Trayectorias ocupacionales de las familias de extrabajadores bananeros en el Pacífico Sur de Costa Rica, durante 1949-2015. (Tesis de Licenciatura en Historia), Universidad de Costa Rica, San José, Costa Rica.

Mesalles, L. (2012). Ni tan bien, ni tan mal... otra vez. San José, Costa Rica: Academia de Centroamérica.

Meza, T. y Smith, D. (1997). Caracterización de los grupos populares del sector económico primario en Costa Rica. Repertorio Americano Nueva época, 3, pp. 102-147.

Molina, I. y Palmer, S. (2008). Costa Rica del siglo XX al XXI: historia de una sociedad. San José, Costa Rica: Editorial EunED.

Muñoz, F. (2018). Memorias de agricultura: despojos y resistencias en el contexto de las transformaciones del Estado Desarrollista en el caso de la comunidad de Potrero Grande de Buenos Aires de Puntarenas 1963-1985. (Tesis de Licenciatura en Sociología), Universidad de Costa Rica, San José, Costa Rica.

Oser, J. y Blanchfield,W. (1980). Historia del pensamiento económico. Madrid: Ediciones Aguilar S.A.

Pardinas, F. (1991). Metodologías y técnicas de investigación en Ciencias Sociales. Distrito Federal: xxI Editores s.A.

Portelli, A. (1991). Lo que hace diferente a la Historia Oral. En D. Schwarzstein (Ed.), La Historia Oral (pp. 36-51). Buenos Aires, Argentina: Centro Editor de América Latina.

Portelli, A. (2004). La orden ya fue ejecutada Roma, las fosas ardeatinas, la memoria. Buenos Aires, Argentina: Fondo de Cultura Económica.

Portelli, A. (2014). Historia Oral, diálogos y géneros narrativos. Anuario de la Escuela de Historia, Universidad Nacional de Rosario, (26), 9-30.

Quesada, R. (2008). Ideas económicas en Costa Rica 1850-2005. San José: Editorial EUNED.

Quezada, J.R. (1990). Historia Oral en Costa Rica: Génesis y estado actual. Estudios sobre las Culturas Contemporáneas, III (9),173-197.

Rajchenberg, E. y Héau-Lambert, C. (enerojunio, 2000). Las mil y una memorias. Bajo el Volcán, Revista del Postgrado en Sociología de la Benemérita Universidad Autónoma de Puebla. Año 1, Primer semestre. Universidad Autónoma de Puebla-México.

Reuben, S. (1982). Capitalismo y crisis económica en Costa Rica. San José, Costa Rica: Editorial El Porvenir.

Ricoeur, P. (1999). La Lectura del Tiempo Pasado: Memoria y Olvido. Madrid, España: Editorial Arrecife.

Ricoeur, P. (2010). La memoria, la historia y el olvido. Distrito Federal, México: Editorial Fondo de Cultura Económica.

Roberti, M. (2011). Rupturas y subjetividades: un acercamiento a las perspectivas de trayectorias laborales. Núcleo básico de revistas Argentinas (Caycit-Conicet), XV (18). 
Roca J. y Martínez L. (2006). Relatar la vida, delatar la identidad. Historia, antropología y fuentes orales, (36), 89-112.

Rodríguez, C. (1993). Tierra de Labriegos: Los campesinos en Costa Rica, desde 1950. San José, Costa Rica: Flacso.

Rodríguez, G., Gil, J. y García J. (1996). Metodología de la Investigación Cualitativa. Granada, España: Aljibe.

Rose N. (1998). The invention of the Self. U.S.A.: University Cambridge Press.

Rovira, J. (2000). Estado y política económica en Costa Rica 1948-1970. San José, Costa Rica: Editorial de la Universidad de Costa Rica.

Royo, A. (noviembre-marzo, 2004). La ocupación del Pacífico Sur costarricense por parte de la compañía bananera (19381984). Diálogos Revista Electrónica de Historia, 4 (2).

Royo, A. (2008). Crisis de dependencia en la Zona Sur: desarrollo agrario y migraciones internas en el Cantón de Os 19732000. San José, Costa Rica: SIEDIN.

Royo, A. (2008). Crisis de dependencia en la Zona Sur: desarrollo agrario y migraciones internas en el cantón de Osa (19732000). San José, Costa Rica: Editorial Universidad de Costa Rica.

Salles, V. (1994). Pobreza, pobreza y más pobre$z a$. Grupo interdisciplinario sobre mujer, trabajo y pobreza. México: Colegio de México.

Sánchez, R. (2004). Estado de bienestar, crisis económica y ajuste estructural en Costa Rica. San José, Costa Rica: Editorial EUNED.

Sandoval, C. (2002) Los otros amenazantes. San José, Costa Rica: Editorial Universidad de Costa Rica.

Sanmartín, R. (2003). Observar, escuchar, comparar, escribir. La práctica de la investigación cualitativa. Barcelona, España: Ariel Antropología.
Santamaría, E. (2011). Trayectorias laborales en los márgenes del empleo, subjetividades y experiencias de los jóvenes en la precariedad laboral. Presidencia del Gobierno Vasco: Eusko Jaurlaritzaren Argitalpen Zerbitzu Nagusia.

Sanz, A. (2005). El método biográfico en investigación social: potencialidades y limitaciones de la fuente oral y los documentos personales. Asclepio, 57, (1).

Smith, A. (1986). La riqueza de las Naciones. Tomo I. San José, Costa Rica: Universidad Autónoma de Centroamérica.

Sojo, C. (2013). Igualiticos. San José, Costa Rica: Editorial EUNED.

Torres, A. (2011). Activación de memoria e identidad colectiva desde la recuperación colectiva de la historia. La Investigación En Las Ciencias Sociales: Estrategias De Investigación, Universidad Piloto de Colombia (p.299-306).

Ugalde, A. (2017). En el fondo el olvido es un gran simulacro: violencia política en la postguerra costarricense (19481958). (Tesis de Postgrado de Historia) Universidad de Costa Rica, San José, Costa Rica.

Van Dijk, T. (2000). Ideología. Una aproximación multidisciplinaria. Barcelona, España: Gedisa.

Vargas, L. (2003). Modelo desarrollista y de industrialización sustitutiva. San José, Costa Rica: Editorial Costa Rica.

Villarreal, A. (enero-junio , 2001). Relaciones de poder en la sociedad patriarcal. Actualidades Investigativas en Educación, 1 (1).

Villasuso, J. (2000). Reformas estructurales y política económica en Costa Rica. Serie reformas económicas, 64. Santiago: CEPAL.

Fecha de ingreso: 04/10/2018 Fecha de aprobación: 14/08/2019 